\section{A caracterização do uso de animais no ensino a partir da percepção de estudantes de ciências biológicas e da saúde}

\section{The characterization of the use of animals in teaching from the perception of students of biological and health sciences}

Thales de A. Tréz

Professor, Instituto de Ciência e Tecnologia/ Universidade Federal de Alfenas.

Rodovia José Aurélio Vilela, 11.999 37715-400 - Poços de Caldas - MG - Brasil thales.trez@unifal-mg.edu.br

Recebido para publicação em abril de 2013. Aprovado para publicação em novembro de 2013.
TRÉZ, Thales de A. A caracterização do uso de animais no ensino a partir da percepção de estudantes de ciências biológicas e da saúde. História, Ciências, Saúde - Manguinhos, Rio de Janeiro, v.22, n.3, jul.-set. 2015, p.863-880.

\section{Resumo}

Animais são utilizados para diversos fins no âmbito científico, sendo destacado nesta pesquisa o emprego no ensino. Objetivando melhor caracterizar esse uso, um questionário foi aplicado a 427 estudantes de medicina, farmácia e ciências biológicas das universidades federais de Santa Catarina e Rio Grande do Sul. Uma série de dados pode ser levantada, como a elevada taxa de sensação de incômodo, e o interesse predominante de apoiar a substituição de animais no âmbito do ensino. Concluímos que o uso de animais para fins didáticos tem alto poder gerador de conflitos - especialmente quando a percepção do sofrimento animal é identificada pelos estudantes. Por fim, três tipos de uso de animais no contexto do ensino são propostos.

Palavras-chave: percepção de estudantes; educação superior; alternativas ao uso de animais; ética; didática.

\section{Abstract}

Animals are used for various purposes in the scientific realm and their use in teaching is highlighted in this research. Seeking to understand this use better, a questionnaire was administered to 427 students of medicine, pharmacy and biological sciences of Santa Catarina and Rio Grande do Sul federal universities. Data was gathered revealing high rates of feelings of discomfort, and the predominant interest in supporting the substitution of animals in the teaching environment. The conclusion reached is that the use of animals for teaching purposes has the ability to generate strong conflict, especially when the perception of animal suffering is identified by the students. Finally, three types of use of animals in the context of teaching are proposed.

Keywords: perception of students; higher education; alternatives to the use of animals; ethics; didactics. 
$\mathrm{O}^{\mathrm{s}}$ $s$ animais utilizados em experimentos didático-científicos compõem uma ampla gama de espécies de vertebrados e invertebrados, variando seu uso conforme os propósitos e a natureza do experimento. Assim, há uma série de tipologias na literatura quanto às finalidades científicas do uso de animais (Yarry, 2005; Taylor et al., jul. 2008; Rollin, 2009; Shanks, Greek, 2009). Shanks e Greek (2009) apresentam nove tipos de uso: (a) como modelos preditivos para enfermidades humanas; (b) como modelos preditivos para a avaliação de risco à exposição de substâncias ou drogas, principalmente no contexto de toxicologia e farmacologia; (c) para uso no ensino; (d) como fonte de peças biológicas (por exemplo: válvula cardíaca de porcos); (e) como reator biológico (na produção de insulina ou anticorpos monoclonais, por exemplo); (f) como fonte de tecidos ou órgãos para estudo de princípios biológicos básicos; (g) como aparato heurístico que possa provocar novas hipóteses biológicas/biomédicas; (h) para beneficiar outros animais não humanos; e (i) para produção de conhecimento científico por si só.

Como esses usos sugerem, a prática da experimentação animal pode ser considerada atividade amplamente disseminada no meio científico e acadêmico (Lima, 2008). Sua trajetória representa séculos na história da humanidade, e seu estabelecimento como prática consolidada pela ciência encontra-se bem descrito na literatura (French, 1999; Shotwell, 2013). Essa prática, no entanto, vem provocando consideráveis preocupações políticas e públicas, e setores da sociedade e da comunidade acadêmica começam a exteriorizar suas opiniões frente aos experimentos que consomem aproximadamente 115 milhões de animais por ano no mundo (Taylor et al., jul. 2008). Para Markus (2008, p.24), o crescente debate dentro da comunidade científica é evidente, levando em consideração os artigos de revistas científicas brasileiras: "O uso de animais em experimentação tem sido debatido de forma intensa".

\section{O uso de animais no ensino}

Dentre as formas de uso mencionadas, podemos destacar a utilização de animais como instrumento didático, ainda bastante adotada nas instituições de ensino superior no Brasil (Tréz, 2008). Nesse âmbito, o emprego de animais para finalidades didáticas difere do uso em pesquisas. No primeiro caso, a finalidade é ilustração ou execução de procedimentos, fenômenos ou habilidades já previamente conhecidos (Smith, 1992), ao passo que na pesquisa, de forma geral, a utilização de animais visa contribuir para compreensão ou elucidação de fenômenos biológicos (pesquisa básica) ou para desenvolvimento de novas drogas, tratamentos ou testes de diagnósticos médicos (pesquisa aplicada).

Um dos campos de conhecimento que mais frequentemente recorrem ao uso de animais é o das ciências biológicas. Estudantes da área são induzidos a promover ou testemunhar a morte de muitos animais ao longo de seu processo de formação. Além das disciplinas que há muito tempo tradicionalmente empregam animais em suas práticas, como a fisiologia, diversas outras também o fazem: zoologia, bioquímica, biofísica, biologia celular, biologia molecular, genética, embriologia, chegando a alguns casos em ecologia e evolução. Na área de ciências da saúde a realidade não é muito diferente. Além das disciplinas básicas que são compartilhadas com a área de ciências biológicas, há ainda a exigência de animais em 
atividades mais específicas, como, por exemplo, no ensino de técnica operatória ou cirúrgica, nos cursos de medicina, ou de farmacologia, nos cursos de farmácia.

Assim, ainda que alguns autores considerem as práticas com animais no ensino "indispensáveis" (Marques et al., 2005, p.265), as situações de conflito provocadas por esse uso vêm-se tornando cada vez mais frequentes em sala de aula (Tréz, 2010b). As pesquisas que se ocupam de investigar a percepção dos estudantes em relação às práticas didáticas com animais sugerem que as possibilidades de conflito são reais e eminentes (Tréz, 2000; Mirault-Pinto, Rímoli, 2005; Barbudo, 2006; Sousa, 2007; Lima, 2008; Tréz e Nakada, 2008; Gomes, 2009; Dias, 2011). Essas pesquisas demonstram, entre outros achados, que uma parcela considerável de estudantes se sente mal ou incomodada com tais procedimentos, é favorável à implementação de métodos substitutivos em sala de aula e apoia a oferta desses métodos a colegas que se opõem ao uso de animais.

Como pano de fundo desse conflito há uma questão de natureza ética que não pode deixar de ser mencionada. A contribuição da corrente da ética animal nesse contexto vem atuando de forma central, pois postula que o círculo de consideração moral para outras espécies animais, além do ser humano, deve ser expandido. Para essa corrente, a nossa relação com os animais é vista como uma questão da moralidade (Felipe, 2007; Paixão, Schramm, 2008).

Feitas essas considerações, o objetivo principal desta pesquisa é caracterizar o uso de animais a partir das percepções de estudantes de graduação das áreas de ciências biológicas e ciências da saúde de duas instituições federais de ensino superior em relação ao emprego de animais para fins didáticos.

O interesse em processos de significação e sentido no âmbito educativo, assim como a preocupação com a dimensão da subjetividade (e os processos de subjetivação) frente a diversos temas de natureza potencialmente conflitiva (como gênero, etnia, classe social, meio ambiente e outros), vem-se consolidando há algum tempo nas produções acadêmicas brasileiras. Nas palavras de Rey (2001, p.2): "Na sala de aulas se geram novos sentidos e significados que são inseparáveis das histórias das pessoas envolvidas, assim como da subjetividade social da escola, na qual aparecem elementos de outros espaços da própria subjetividade social".

Há pouco mais de 10 anos, soma-se a essa produção uma linha de investigação que procura captar a percepção de diversos sujeitos perante o uso de animais em experimentos didáticocientíficos, levantando questões acerca do papel que os métodos didáticos que empregam animais cumprem na formação dos sujeitos (Tréz, 2000; Mirault-Pinto, Rímoli, 2005; Barbudo, 2006; Sousa, 2007; Lima, 2008; Tréz, Nakada, 2008; Dias, 2011). Nesse tipo de abordagem, as diferentes concepções dos sujeitos sobre vida, animais e ética vêm-se destacando como de principal interesse, visando identificar possíveis divergências e congruências em relação aos parâmetros estabelecidos culturalmente, que normatizam e naturalizam tais percepções. Junto a esse objetivo, as abordagens não costumam abrir mão de uma análise crítica que pretende problematizar tais naturalizações, que às vezes abrem espaço, de forma propositiva, para um novo campo de significados e conceitos (Tréz, 2010b). 


\section{O caminhar da pesquisa}

A abordagem desta pesquisa se dá dentro dos moldes da pesquisa quantitativa, descritiva, do tipo survey (levantamento), de corte transversal. Freitas et al. (2000, p.105) definem esse tipo de método como sendo um que visa "à obtenção de dados ou informações sobre características, ações ou opiniões de determinado grupo de pessoas, indicado como representante de uma população-alvo, por meio de um instrumento de pesquisa, normalmente um questionário".

O instrumento utilizado nessa etapa foi um questionário anônimo, estruturado, com predominância de questões fechadas e lógica interna de direcionamento. ${ }^{1}$ Nas questões fechadas, fez-se o uso ainda de questões de escala Likert de cinco pontos, como veremos a seguir. Segundo Pereira (2004, p.65), tal escala é sensível a elementos qualitativos: "Reconhece a oposição entre contrários, reconhece gradiente, e reconhece situação intermediária”. Essa escala "funciona particularmente bem no contexto de uma série de perguntas que procuram obter informações sobre atitudes a respeito de um assunto específico" (Rea, Parker, 2000, p.70). As questões foram assim apresentadas:

1. Sobre o uso de animais, ${ }^{2}$ você já sentiu algum tipo de incômodo durante aulas em sua graduação, em relação ao animal que estava sendo experimentado?

(A) Todas as vezes que eu participei / (B) Algumas vezes - dependendo do animal / (C) Algumas vezes - independente do animal / (D) Eu intencionalmente não participei dessas aulas / (E) Nunca (vá para Q2) / (F) Não me lembro/não sei (vá para Q2) / (G) Nunca participei de uma aula desse tipo (vá para Q3).

1.1. Se D (na Q1), descreva brevemente a principal razão para não ter participado [aberta].

1.2. Se A, B ou C (na Q1), descreva brevemente a principal razão para o incômodo [aberta].

1.3. Se A, B ou C (na Q1), qual a relevância desse incômodo para você?

(A) Muito relevante / (B) Relevante / (C) Pouco relevante (vá para Q2) / (D) Irrelevante (vá para Q2) / (E) Não sei, não estou seguro (vá para Q2).

1.3.1. Se A ou B (na Q1.3), você fez alguma coisa a respeito? ( ) Sim / ( ) Não (pule a próxima questão).

1.3.1.1. Se "Sim" (na Q1.3.1), descreva brevemente o que você fez (ao final, vá para Q2) [aberta].

1.3.1.2. Se "Não" (na Q1.3.1), qual seria a principal razão para não ter feito nada? (selecione até duas opções) (A) Desconheço outros métodos alternativos/

(B) Não sinto abertura suficiente em sala de aula pra expor meus pensamentos sobre o assunto / (C) Não me sinto confiante o suficiente para expor meus pensamentos sobre o assunto / (D) Receio que possa haver alguma reação negativa de meus colegas e/ou professores / (E) Outro (especifique, por favor) [aberta].

Nas próximas questões, escolha o grau de concordância ou discordância que mais se aproxime de sua opinião [questões de escala Likert de cinco pontos: Concordo Fortemente / Concordo / Nem Concordo Nem Discordo / Discordo / Discordo Fortemente]. 
2. Do ponto de vista ético, o uso de animais no ensino não se justifica.

3. Não vejo problemas com o uso de animais no ensino, uma vez que esteja de acordo com a legislação que o regulamente.

4. Não existe outro caminho para aprendizagem tão bom ou eficiente quanto a prática com animais.

5. Estudantes contrários ao uso de animais em práticas educativas deveriam ter o direito de não participar de tais aulas.

6. Eu apoiaria e participaria de atividades que promovessem a substituição do uso de animais no ensino.

6.1. Se CF ou C (na Q6), até que ponto você iria? (selecione quantas quiser.)

(A) Assinar um abaixo-assinado / (B) Doar dinheiro / (C) Participar de uma passeata /

(D) Questionar o professor / (E) Promover debates em sala / (F) Resgatar animais em laboratórios / (G) Apresentar oficialmente sua objeção ao uso de animais para sua faculdade.

A aplicação desse instrumento ocorreu com estudantes de graduação dos cursos de medicina, farmácia e ciências biológicas da Universidade Federal de Santa Catarina (UFSC) e Universidade Federal do Rio Grande do Sul (UFRGS). O projeto de pesquisa foi submetido à apreciação dos comitês de ética em pesquisa com seres humanos de ambas as instituições. Após o parecer favorável das duas instâncias, a coordenação de cada um dos cursos foi contatada, solicitando a autorização para aplicação dos questionários em horário de aula, bem como a indicação de professores para viabilizar sua aplicação. Com o parecer positivo por parte das coordenações, os professores indicados foram contatados. Os semestres/fases iniciais dos cursos foram desconsiderados na pesquisa, e deu-se preferência a estudantes cursando a segunda metade do respectivo curso. Sendo o agendamento feito com cada um dos professores, houve então a aplicação do questionário. Nesse, uma folha de rosto destacável explicava detalhes da pesquisa e dava instruções para seu preenchimento. As aplicações ocorreram entre abril e agosto de $2011 .^{3}$

Todos os dados obtidos dos questionários foram tabulados em planilhas específicas para cada grupo e tratados estatisticamente (cálculo normal de distribuição e frequência). Dados de questões abertas foram tratados com ajuda do programa NVivo, ${ }^{4}$ no processo de categorização dos textos.

\section{A indicação dos dados da pesquisa}

Conforme mencionado na seção anterior, esta pesquisa foi feita com estudantes dos cursos de medicina, farmácia e ciências biológicas da UFSC e da UFRGS - a partir de agora indicados, respectivamente, como MeSC, FaSC, BiSC (para os cursos da UFSC) e MeRS, FaRS, BiRS (para os cursos da UFRGS). A tabela de responsividade da amostragem encontra-se a seguir (Tabela 1).

Uma consideração inicial a respeito do percentual de responsividade: apesar de relativamente baixo dentro de cada curso em relação ao número total de estudantes (em torno de $10 \%)$, o recorte da pesquisa procurou dar preferência aos estudantes a partir da segunda 
metade do curso, com uma vivência maior de formação. Assim, há uma característica mais qualitativa da amostragem.

O incômodo em relação ao animal sendo experimentado, bem como a relevância dessa reação, está apresentado na Tabela 2. A proporção de estudantes que nunca sentiram nenhum desconforto foi mais acentuada na FaSC. Nos demais grupos, a maioria dos estudantes relatou haver sentido incômodo, sendo que a sinalização de "muito relevante ou relevante" para o desconforto experimentado foi maior que a sinalização para o incômodo "pouco relevante ou irrelevante" em todos os cursos, com exceção da FaRS.

Tabela 1: Índices de responsividade para os cursos de graduação amostrados

\begin{tabular}{|l|l|l|l|l|l|l|}
\hline \multirow{2}{*}{} & \multicolumn{2}{|l|}{ UFRGS } & UFSC \\
\cline { 2 - 7 } & $\mathrm{nR}^{*}$ & $\mathrm{nT}^{*}$ & $\% \mathrm{~T}^{*}$ & $\mathrm{nR}^{*}$ & $\mathrm{nT}^{*}$ & $\% \mathrm{~T}^{*}$ \\
\hline Farmácia & 51 & 450 & $11,3 \%$ & 63 & 609 & $10,3 \%$ \\
\hline Ciências biológicas & 64 & 596 & $10,7 \%$ & 50 & 374 & $13,3 \%$ \\
\hline Medicina & 89 & 863 & $10,3 \%$ & 110 & 610 & $14,6 \%$ \\
\hline Total de respondentes & 204 & 223 & \\
\hline
\end{tabular}

* nR: número de respondentes; nT: total de estudantes matriculados no curso; \%T: percentual em relação ao total.

Fonte: Dados obtidos com as coordenadorias de graduação em março de 2011.

Tabela 2: A sensação de incômodo, por quem alegou haver utilizado animais em aulas práticas

\begin{tabular}{|l|l|l|l|l|l|l|}
\hline & BiSC & BiRS & MeSC & MeRS & FaSC & FaRS \\
\hline Relevância do incomodo* & $66 \%-17 \%$ & $42 \%-28 \%$ & $37 \%-19 \%$ & $29 \%-27 \%$ & $27 \%-19 \%$ & $27 \%-42 \%$ \\
\hline Nunca sentiram & $10 \%$ & $21 \%$ & $43,5 \%$ & $37,3 \%$ & $53,8 \%$ & $23,1 \%$ \\
\hline
\end{tabular}

* Muito Relevante+Relevante e Pouco Relevante+Irrelevante.

Fonte: Tabela elaborada pelo autor.

Além de identificar a frequência de alegação de incômodo como significativa entre todos os respondentes (dos que participaram de práticas com animais, 63,5\% declararam haver sentido algum tipo de desconforto), temos ainda que a maioria considerou o incômodo relevante ou muito relevante $(60 \%)$.

Outras pesquisas que identificam frequência significativa (quando não majoritária) de "sensações negativas" entre estudantes de ciências biológicas e da saúde podem ser encontradas (Tréz, 2000; Diniz et al., 2006; Barbudo, 2006; Tréz, Nakada, 2008; Gomes, 2009; Dias, 2011). Por exemplo, sensações de angústia, agonia, ansiedade e tristeza foram detectadas com certa frequência na pesquisa de Diniz et al. (2006). Nessa mesma pesquisa, cerca de 50\% dos alunos do curso de medicina indicaram "sentimentos negativos" relacionados ao uso de animais em práticas - com considerável variação entre mulheres (60,8\%) e homens (30,6\%). Neste estudo, uma variação também foi observada em relação à sensação de desconforto entre os gêneros. $\mathrm{Na}$ medicina, a frequência de incômodo entre os que participaram de aulas com animais foi de $65 \%$ para as mulheres e $48 \%$ para os homens. Levando em conta todos os cursos, o incômodo foi alegado por $72 \%$ das mulheres e $49 \%$ dos homens. Ainda, consideraram o desconforto como relevante ou muito relevante $46 \%$ das mulheres e $27 \%$ dos homens. 
Gomes (2009), analisando estudantes de ciências biológicas e da saúde, verificou que $41 \%$ deles alegaram haver sentido algum tipo de incômodo moral ou físico durante os procedimentos, com considerável variação entre cursos (por exemplo, 69\% no curso de biologia e 30\% no curso de medicina).

Ainda em relação ao incômodo, a Tabela 3 indica três aspectos dessa sensação, discriminados nas seguintes opções para a questão: "Todas as vezes que eu participei", "algumas vezes independente do animal" e "algumas vezes - dependendo do animal".

Tabela 3: Percentual de estudantes que, havendo participado de aulas práticas, indicaram sensação de incômodo entre as três opções oferecidas

\begin{tabular}{|c|c|c|c|c|c|c|}
\hline & $\begin{array}{c}\text { BiSC } \\
n=29^{*}\end{array}$ & $\begin{array}{c}\text { BiRS } \\
\mathrm{n}=57^{*}\end{array}$ & $\begin{array}{l}\text { MeSC } \\
n=85^{*}\end{array}$ & $\begin{array}{l}\text { MeRS } \\
\mathrm{n}=51^{*}\end{array}$ & $\begin{array}{c}\text { FaSC } \\
n=26^{*}\end{array}$ & $\begin{array}{c}\text { FaRS } \\
n=26^{*}\end{array}$ \\
\hline Sempre & $31 \%$ & $16 \%$ & $9 \%$ & $12 \%$ & $12 \%$ & $8 \%$ \\
\hline Ocasional, independente do animal & $24 \%$ & $23 \%$ & $21 \%$ & $22 \%$ & $23 \%$ & $46 \%$ \\
\hline Ocasional, dependendo do animal & $28 \%$ & $33 \%$ & $26 \%$ & $24 \%$ & $12 \%$ & $15 \%$ \\
\hline
\end{tabular}

* $\mathrm{n}$ é o número de estudantes que alegou haver participado de aulas práticas com animais.

Fonte: Tabela elaborada pelo autor.

A opção "eu intencionalmente não participei dessas aulas", na mesma questão, foi sinalizada por dois estudantes no curso de BiSC, um no curso de BiRS e três no curso de MeSC. Indagados sobre a principal razão de não haver participado (Questão 1.1), as justificativas foram:

BiSC: Eu não acho a experimentação, no caso a dissecação de animais, necessária para fins didáticos.

BiRS: Porque sei que não há absolutamente nenhuma necessidade. Existem métodos substitutivos, nunca fui obrigada a participar e nem fui prejudicada. Mas acho que há ainda muita intolerância e ignorância sobre o assunto.

MeSC: O sofrimento que o animal tem não vale o aprendizado, e existem outras técnicas eficazes de aprendizado que não utilizam vidas./Acho desnecessário o uso de animais na educação, além de me sentir mal com seu uso./Sofrimento de animal desnecessário para os fins pedagógicos projetados.

Observamos, em praticamente todas as manifestações, posicionamento crítico bastante categórico quanto à necessidade de tal emprego de animais - o que pode ser esperado, de fato, de um estudante que intencionalmente se abstém de participar de tais aulas (ainda que a abstenção possa ser motivada por outros fatores).

A descrição da principal razão para o desconforto, para aqueles que declararam haver sentido incômodo todas ou algumas vezes em que participaram das aulas (na Questão 1), foi também aberta. Categorias foram criadas para agrupar os tipos de respostas, e as mais frequentes estão descritas no Quadro 1, em ordem decrescente de frequência.

Podemos observar que a questão do sofrimento animal parece ser central como razão do incômodo. Pelo menos duas explicações podem ser elaboradas a partir daí. A primeira é a de que há uma evidente inadequação do ponto de vista do manuseio e da condução da experiência, seja por despreparo profissional, seja por imprevistos na execução dela - o que, nos dois casos, configuraria uma situação de maus-tratos. A segunda é a de que há uma percepção 
mais sensível e/ou crítica por parte do estudante em relação ao que é o sofrimento animal. Seja como for, chama a atenção que quase 1/3 dos estudantes do MeSC indicam a percepção de sofrimento animal localizada especificamente na disciplina de técnica cirúrgica - o que precisa ser mais bem apurado em outra pesquisa.

Dos estudantes que consideraram seu incômodo relevante ou muito relevante (Tabela 2), indagou-se se foi tomado algum tipo de atitude a respeito (Questão 1.3.1) e, em caso positivo,

Quadro 1: Frequência e descrição de categorias para a principal razão do alegado incômodo

\begin{tabular}{|c|c|c|}
\hline Categoria & Descrição & Entradas \\
\hline $\begin{array}{l}\text { Percepção de } \\
\text { sofrimento }\end{array}$ & 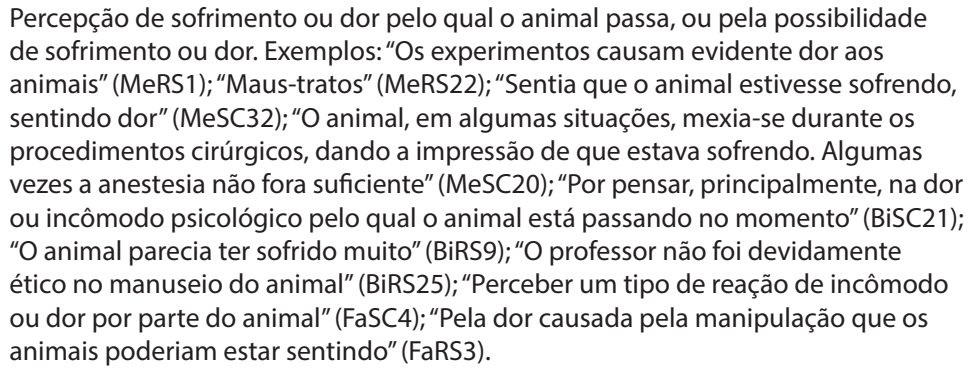 & $\begin{array}{l}\text { Total: } 68 \\
\text { MeSC: } 28 \\
\text { MeRS: } 15 \\
\text { BiRS: } 12 \\
\text { BiSC: } 8 \\
\text { FaSC: } 3 \\
\text { FaRS: } 2\end{array}$ \\
\hline $\begin{array}{l}\text { Sensação } \\
\text { negativa }\end{array}$ & $\begin{array}{l}\text { Percepção negativa em relação ao procedimento, com indicação de sentimento } \\
\text { de pena ou angústia, por exemplo. Exemplos: "Não gosto de ver animais sendo } \\
\text { sacrificados" (BiRS17); "Receio. Não sabia se o animal estava sofrendo ou não” } \\
\text { (MeSC12);"Acho uma tortura” (MeRS13); "Pena” (FaRS14, FaSC1, BiSC3). }\end{array}$ & $\begin{array}{l}\text { Total: } 24 \\
\text { BiRS: } 6 \\
\text { MeSC: } 5 \\
\text { MeRS: } 4 \\
\text { FaRS: } 4 \\
\text { FaSC: } 3 \\
\text { BiSC: } 2\end{array}$ \\
\hline $\begin{array}{l}\text { Proximidade } \\
\text { com o } \\
\text { humano }\end{array}$ & $\begin{array}{l}\text { Algum tipo de proximidade com o ser humano (filogenética ou cotidiana) ou } \\
\text { empatia. Exemplos:"O incômodo provavelmente se deu pelo fato de o animal } \\
\text { em questão ser um cachorro e eu sempre tive cachorros de estimação" (MeSC24); } \\
\text { "Incômodo com uso de animais domésticos" (FaRS11);"Acredito que o incômodo } \\
\text { foi mais pela semelhança/proximidade da espécie com a espécie humana" } \\
\text { (BiSC18);"O rato era 'fofo'. Era como se ele fosse um animal de estimação" (BiRS19); } \\
\text { "Empatia com o animal" (MeRS14). }\end{array}$ & $\begin{array}{l}\text { Total: } 24 \\
\text { MeSC: } 9 \\
\text { FaRS: } 6 \\
\text { BiSC: } 3 \\
\text { BiRS: } 3 \\
\text { MeRS: } 3\end{array}$ \\
\hline $\begin{array}{l}\text { Falta de } \\
\text { justificativa } \\
\text { ou } \\
\text { necessidade }\end{array}$ & $\begin{array}{l}\text { Desnecessidade do experimento ou ausência de justificativa aceitável. Exemplos: } \\
\text { "Sentir maltratando o animal sem uma finalidade didática relevante" (MeSC37); } \\
\text { "Falta de justificativa (e nem razoável) para a morte ou uso daquele animal" } \\
\text { (BiSC2); "Não achei necessário o uso dos animais para demonstrar e explicar a } \\
\text { matéria" (BiRS30); "Desnecessidade do experimento" (MeRS19). }\end{array}$ & $\begin{array}{l}\text { Total: } 16 \\
\text { MeSC: } 6 \\
\text { BiSC: } 5 \\
\text { BiRS: } 4 \\
\text { MeRS:1 }\end{array}$ \\
\hline $\begin{array}{l}\text { Morte do } \\
\text { animal }\end{array}$ & $\begin{array}{l}\text { Relativo ao testemunho ou aos procedimentos de indução de morte. Exemplos: } \\
\text { "É incômodo saber que vários animais serão mortos" (BiRS8); "Saber que o animal } \\
\text { morreria" (MeSC31); "Tive incômodo ao matar o animal após o experimento" } \\
\text { (FaSC10); "Vi um hamster sendo guilhotinado após teste de anticonvulsivante. } \\
\text { Incomodei-me um pouco" (MeRS15). }\end{array}$ & $\begin{array}{l}\text { Total: } 12 \\
\text { BiRS: } 7 \\
\text { MeSC: } 2 \\
\text { FaSC: } 2 \\
\text { MeRS: } 1\end{array}$ \\
\hline $\begin{array}{l}\text { Uso de } \\
\text { alternativas }\end{array}$ & $\begin{array}{l}\text { Possibilidade de substituição dos procedimentos didáticos. Exemplos: "O incômodo } \\
\text { se deu, pois o uso poderia ser facilmente substituído por outro método" (BiSC23); } \\
\text { "Porque achava desnecessário utilizar um animal para explicar alguma teoria que } \\
\text { seria completamente possível de explicar com outra metodologia" (BiRS16);“Uma } \\
\text { aula que poderia muito bem ser explicada apenas na teoria" (FaRS2). }\end{array}$ & $\begin{array}{l}\text { Total: } 10 \\
\text { BiSC: } 5 \\
\text { BiRS: } 4 \\
\text { FaRS: } 1\end{array}$ \\
\hline $\begin{array}{l}\text { Percepção } \\
\text { ética }\end{array}$ & $\begin{array}{l}\text { Fundamentação ética. Exemplos: "Penso no direito à vida que aquele ser tem e se } \\
\text { tenho o'poder' de ser superior a ele" (BiRS14);"A sensação de fazer de um ser vivo um } \\
\text { objeto, sendo indiferente aos seus sentimentos" (MeSC18); "São seres que merecem } \\
\text { respeito e dignidade" (MeRS6);"Ver o indefeso do animal, um ser que possui } \\
\text { sentimentos como nós e é incapaz de se defender perante o homem" (FaRS12). }\end{array}$ & $\begin{array}{l}\text { Total: } 10 \\
\text { BiRS: } 4 \\
\text { MeSC: } 4 \\
\text { MeRS: } 1 \\
\text { FaRS: } 1\end{array}$ \\
\hline
\end{tabular}


solicitou-se a descrição da ação (Questão 1.3.1.1). A Tabela 4 sintetiza as respostas a essas duas questões. Em ambos os cursos de farmácia não houve sinalização de qualquer tipo de ação.

Na Tabela 4, além de percebermos que a minoria dos estudantes decide por algum tipo de intervenção contrária à prática em questão, podemos identificar ainda que o questionamento ao professor é a intervenção mais recorrente, seguida do abandono da aula.

Caso o estudante indicasse que não havia feito algo a respeito das práticas (mesmo tendo considerado o incômodo "muito relevante"/"relevante"), solicitou-se que indicasse o(s) motivo(s) para essa decisão (Questão 1.3.1.2). A Tabela 5 ilustra a distribuição das opções assinaladas.

Tabela 4: Respostas para a questão sobre o tipo de atitude adotado

\begin{tabular}{|l|l|l|}
\hline \multicolumn{2}{|l|}{ Fez algo a respeito* } & Descrição \\
\hline BiSC & $31,5 \%$ & $\begin{array}{l}\text { - Questionamento com o professor da disciplina (três entradas); } \\
\text { - Abandono ou não comparecimento à aula (duas entradas); } \\
\text {-"Por exemplo, ao visitar um laboratório da farmacologia e observar o } \\
\text { tratamento dos ratos, desisti de atuar no ramo da imunologia". }\end{array}$ \\
\hline BiRS & $21 \%$ & $\begin{array}{l}\text { - Questionamento com o professor da disciplina (duas entradas); } \\
\text { - Abandono da aula (duas entradas); } \\
\text {-"Fiz a prática ser mudada por uma exibição de um vídeo". }\end{array}$ \\
\hline MeSC & $19 \%$ & $\begin{array}{l}\text { - Questionamento com o professor da disciplina (quatro entradas); } \\
\text { - Debate com colegas (uma entrada); } \\
\text { - "Tentei não participar ativamente na atividade, apenas observar". }\end{array}$ \\
\hline MeRS & $20 \%$ & $\begin{array}{l}\text { - Questionamento com o professor da disciplina (uma entrada); } \\
\text { - Abandono da aula (uma entrada); } \\
\text { - "Evitei prestar atenção". }\end{array}$ \\
\hline
\end{tabular}

* Em relação ao número de estudantes que declararam a sensação de incômodo como relevante ou muito relevante. Fonte: Tabela elaborada pelo autor.

Tabela 5: Sinalizações para as opções referentes à Questão 1.3.1.2

\begin{tabular}{|c|c|c|c|c|c|c|c|}
\hline Opção & BiSC & BiRS & MeSC & MeRS & FaSC & FaRS & Total \\
\hline$A^{*}$ & 4 & 5 & 6 & 4 & 2 & 2 & 23 \\
\hline$B^{*}$ & 4 & 6 & 6 & 5 & 2 & 2 & 25 \\
\hline$C^{*}$ & 7 & 5 & 7 & 3 & 3 & 0 & 25 \\
\hline$D^{*}$ & 2 & 7 & 6 & 2 & 2 & 3 & 22 \\
\hline$E^{*}$ & 2 & 2 & 7 & 1 & 0 & 1 & 13 \\
\hline
\end{tabular}

* A: Desconheço outros métodos alternativos; B: Não sinto abertura suficiente em sala de aula para expor meus pensamentos sobre o assunto; $C$ : Não me sinto confiante o suficiente para expor meus pensamentos sobre o assunto; D: Receio que possa haver alguma reação negativa de meus colegas e/ou docentes; E: Outro (especifique, por favor). Fonte: Tabela elaborada pelo autor.

Podemos observar que houve distribuição variada entre os cursos, sendo a opção C mais destacada no BiSC. Nos outros cursos a variação entre as opções foi mais difusa. Uma quinta opção aberta ("outro") foi também sinalizada pelos respondentes, permitindo uma leitura mais qualitativa da questão. No MeSC, por exemplo, essa opção esteve entre as mais sinalizadas, e podemos encontrar entradas que procuram enfaticamente justificar a não intervenção. 
A ideia de "necessidade" se fez bastante presente nessas entradas, como podemos observar nos exemplos de diferentes respondentes do mesmo curso: "Não há métodos alternativos que proporcionem igual conhecimento prático"; "Foi preciso utilizar animais para tentar mais tarde salvar vidas humanas, por isso não fiz nada a respeito"; "Necessidade de aprendizado"; "Não acredito que métodos alternativos possam substituir o experimento com animais"; "Acredito que, apesar do desconforto, há necessidade do procedimento em animais para o aprendizado".

Cinco questões de escala Likert relativas ao uso de animais no ensino também foram aplicadas aos estudantes de graduação. Aos dados obtidos dessa escala, foi empregada uma análise, por questão, que procurou identificar o predomínio das ênfases (Concordância e Discordância Fortes - CF/DF) na distribuição das respostas. Assim, quando o total de respostas CF/DF é maior ou igual ao total de respostas C/D (Concordância/Discordância), considera-se um posicionamento com ênfase forte (CF ou DF). Já a ênfase moderada ocorre quando o total de respostas CF/DF é menor do que o total de respostas C/D. Dito isso, vamos aos resultados e à discussão de cada uma das questões Likert.

Afirmação 1: "Do ponto de vista ético, o uso de animais no ensino não se justifica" Tabela 6: Porcentagem de Concordo (C), Discordo (D) e Nem Concordo Nem Discordo (NCND)
entre estudantes de graduação em relação à afirmação 1

\begin{tabular}{|l|r|r|r|}
\hline Curso & \multicolumn{1}{|c|}{ C } & \multicolumn{1}{c|}{ D } & \multicolumn{1}{c|}{ NCND } \\
\hline BiSC & $\mathbf{7 6} \% *$ & $6 \%$ & $18 \%$ \\
\hline BiRS & $29,7 \%$ & $\mathbf{5 0} \%$ & $20,3 \%$ \\
\hline MeSC & $16,9 \%$ & $\mathbf{6 8 , 5} \%$ & $14,6 \%$ \\
\hline MeRS & $22,7 \%$ & $\mathbf{7 0} \%$ & $7,3 \%$ \\
\hline FaSC & $11,1 \%$ & $\mathbf{5 8 , 7} \%$ & $30,2 \%$ \\
\hline FaRS & $21,6 \%$ & $\mathbf{5 6 , 9} \%$ & $21,5 \%$ \\
\hline
\end{tabular}

* Ênfase moderada.

A discordância majoritária observada na maioria dos grupos para essa afirmação (conforme a Tabela 6) sugere a existência de justificações de natureza ética para a utilização de animais com fins de ensino. Tal justificativa de fato procede; porém, seja ela qual for, deve estar calcada em pressupostos antropocêntricos, ${ }^{5}$ para ser coerente com a ação de tirar a vida de animais a fim de atender a um interesse humano (no caso, o de aprender determinado conhecimento ou habilidade). A ação de tirar a vida de um animal para a aquisição de conhecimentos ou habilidades já sabidas também compromete as bases desse tipo de fundamentação moral mais tradicional - agravado pela possibilidade de substituição de animais por métodos ou modelos alternativos. Tomemos como exemplo o caso do uso de animais para o ensino de técnica operatória para a medicina humana. Comentários espontâneos - recebidos em um campo próprio do questionário - de estudantes desse curso afirmam categoricamente a necessidade desse uso, como, por exemplo: "Considero fundamental sua utilização na disciplina de técnica operatória. Se eu não tivesse treinado em um animal, minha primeira sutura teria sido em um ser humano de 5 anos na Emergência de um hospital da cidade" 
(MeSC4). O estudante se refere ao uso de cães da raça beagle, utilizados em uma disciplina oferecida pelo curso de medicina da mencionada universidade. No entanto, como justificar eticamente esse uso quando o curso de medicina da UFRGS, desde 2007, não utiliza mais animais em disciplina equivalente? O então diretor dessa faculdade, Mauro Antônio Czepielewski, afirmou na ocasião: "Abolimos o uso de animais porque hoje não se precisa mais disso". Geraldo Sidiomar Duarte, à época diretor do Departamento de Cirurgia, assim colocou: "Há modelos artificiais para todos os tipos de treinamento, pode-se montar um laboratório gigantesco com eles. Estamos muito satisfeitos, e os alunos muito mais" (Nenê, 13 jul. 2009). Além dessa questão, o diretor afirmou ainda que, quanto à questão ética, a pressão da sociedade civil organizada foi também considerada.

Ainda assim, seja na concordância ou na discordância em relação à afirmação, por se tratar de um juízo de natureza ética, surgiu a necessidade de examinar detalhadamente a fundamentação filosófica que acompanha e sustenta esses posicionamentos, a fim de melhor compreendê-los - uma análise que se fez limitada pela presente abordagem quantitativa.

Afirmação 2: "Não vejo problemas com o uso de animais no ensino, uma vez que esteja de acordo com a legislação que o regulamente"

\section{Tabela 7: Porcentagem de Concordo (C), Discordo (D) e Nem Concordo Nem Discordo (NCND) entre estudantes de graduação em relação à afirmação 2}

\begin{tabular}{|l|r|r|r|}
\hline Curso & \multicolumn{1}{c|}{ C } & \multicolumn{1}{c|}{ D } & NCND \\
\hline BiSC & $14 \%$ & $\mathbf{7 8} \%$ & $8 \%$ \\
\hline BiRS & $\mathbf{5 3 , 1 \% *}$ & $29,7 \%$ & $17,2 \%$ \\
\hline MeSC & $\mathbf{6 9 , 7 \% * *}$ & $23,6 \%$ & $6,7 \%$ \\
\hline MeRS & $\mathbf{7 0 \% *}$ & $22,7 \%$ & $7,3 \%$ \\
\hline FaSC & $\mathbf{7 6 , 2 \% *}$ & $14,3 \%$ & $9,5 \%$ \\
\hline FaRS & $\mathbf{8 4 , 3} \%$ & $11,8 \%$ & $3,9 \%$ \\
\hline
\end{tabular}

* Ênfase moderada. ** Ênfase forte. Fonte: Tabela elaborada pelo autor.

Novamente, com exceção da BiSC, o restante dos grupos sinalizou concordância com a afirmação (Tabela 7). As ênfases na concordância foram observadas em quatro grupos. Ao contrário da primeira afirmação, e pelo já exposto, podemos considerar que os que concordam com essa sentença pendem para uma leitura legalista do assunto, sugerindo a ideia de que a legislação é uma garantia de ações moralmente corretas, assim como reduzindo o alcance do debate em seus potenciais horizontes. Como afirma Hegel (1997, p.90), "o Estado não é a condição necessária da justiça em si". E a julgar pela ênfase com que se manifestam os cursos com predomínio pela concordância, podemos ter uma ideia da perfusão desse posicionamento. Quanto ao alcance do debate, outras considerações, mais próprias de uma análise jurídico-filosófica relativamente contemporânea, poderiam ser desdobradas nessa questão; considerações que dizem respeito ao discurso que toma os animais apenas sob uma perspectiva utilitária, representada pelo vocabulário que lhes nega a personalidade jurídica, lhes confere o status de coisa, objeto, propriedade, recursos naturais ou bens de uso comum. ${ }^{6}$ 
Afirmação 3: "Não existe outro caminho para a aprendizagem tão bom ou eficiente quanto a prática com animais"

Tabela 8: Porcentagem de Concordo (C), Discordo (D) e Nem Concordo Nem Discordo (NCND) entre estudantes de graduação em relação à afirmação 3

\begin{tabular}{|l|r|r|r|}
\hline Curso & \multicolumn{1}{|c|}{ C } & \multicolumn{1}{c|}{ D } & \multicolumn{1}{c|}{ NCND } \\
\hline BiSC & $\mathbf{8} \%$ & $\mathbf{8 8} \%^{*}$ & $4 \%$ \\
\hline BiRS & $31,3 \%$ & $\mathbf{4 8 , 4 \% * *}$ & $20,3 \%$ \\
\hline MeSC & $37,1 \%$ & $\mathbf{4 2 , 7} \%$ & $20,2 \%$ \\
\hline MeRS & $24,5 \%$ & $\mathbf{5 1 , 8 \% * *}$ & $23,7 \%$ \\
\hline FaSC & $31,7 \%$ & $\mathbf{3 4 , 9 \%}$ & $33,4 \%$ \\
\hline FaRS & $15,7 \%$ & $\mathbf{5 4 , 9 \% * *}$ & $29,4 \%$ \\
\hline
\end{tabular}

*Ênfase forte; ** Ênfase moderada.

Fonte: Tabela elaborada pelo autor.

A discordância majoritária observada em todos os grupos para essa afirmação (Tabela 8) sugere o reconhecimento de outras formas de aprender conteúdos ou habilidades que não necessariamente envolvam o uso de animais. Esse dado é coerente com aqueles apresentados na Tabela 5, na qual o desconhecimento de métodos alternativos não foi mencionado com frequência. A afirmação nessa questão abre a discussão sobre o papel dos métodos alternativos de ensino como possibilidade na formação de profissionais da área da saúde e das ciências biológicas. Podemos dizer que os métodos substitutivos fazem parte de um processo maior de inovação e atualização no campo do ensino-aprendizagem. Eles trazem em sua concepção, além da proposta de diversidade didática, um chamado para a revisão dos instrumentos e das abordagens tradicionais, diante das já existentes problematizações (Balcombe, 2000).

Os métodos substitutivos para o uso de animais no ensino podem ser caracterizados em duas categorias principais: instrumento e abordagem (Tréz, 2010a). A primeira categoria é constituída de filmes e vídeos; modelos, manequins e simuladores; simulação computadorizada multimídia; e tecnologia in vitro. Já a segunda categoria diz respeito à obtenção ética de cadáveres e tecidos; ao trabalho clínico com pacientes e voluntários; à autoexperimentação; e aos estudos de campo. Essas abordagens são mais amplas e assumem dimensões para além da didático-instrumental. ${ }^{7}$

Considerando uma boa compreensão dessa afirmação e a ênfase presente nos posicionamentos discordantes, uma questão pode nos dar pistas sobre o comportamento das afirmações anteriores: reconhecendo outros caminhos tão bons ou eficientes quanto a prática com animais, como é possível justificar ética e legalmente o uso?

Afirmação 4: "Estudantes contrários ao uso de animais em práticas educativas deveriam ter o direito de não participar de tais aulas" 
Tabela 9: Porcentagem de Concordo (C), Discordo (D) e Nem Concordo Nem Discordo (NCND) entre estudantes de graduação em relação à afirmação 4

\begin{tabular}{|l|r|r|r|}
\hline Curso & \multicolumn{1}{|c|}{ C } & \multicolumn{1}{c|}{ D } & \multicolumn{1}{c|}{ NCND } \\
\hline BiSC & $\mathbf{9 4 \% *}$ & $0 \%$ & $6 \%$ \\
\hline BiRS & $\mathbf{8 4 , 4 \% *}$ & $\mathbf{7 , 8} \%$ & $\mathbf{7 , 8} \%$ \\
\hline MeSC & $\mathbf{8 5 , 4 \% *}$ & $3,4 \%$ & $11,2 \%$ \\
\hline MeRS & $\mathbf{8 4 , 5 \% *}$ & $6,4 \%$ & $9,1 \%$ \\
\hline FaSC & $\mathbf{6 5 , 1 \%}$ & $23,8 \%$ & $11,1 \%$ \\
\hline FaRS & $\mathbf{7 6 , 5 \% * *}$ & $11,8 \%$ & $11,7 \%$ \\
\hline
\end{tabular}

* Ênfase forte; ** Ênfase moderada.

Fonte: Tabela elaborada pelo autor.

Como vemos na Tabela 9, o padrão de sinalização apontou para a concordância em todos os grupos, com ênfase na maioria deles. Esse dado indica que há reconhecimento da legitimidade, por parte da maioria dos estudantes, da postura objetora, que deve ser atendida. Segundo Levai e Rall (2008, p.59-60),

a lei brasileira possibilita ao estudante ou ao funcionário que eventualmente lide com experimentação animal sua recusa em participar de aulas de vivissecção ou de quaisquer testes com animais em centros de pesquisa, desde que invocada a escusa de consciência. Afinal, ninguém pode ser obrigado a fazer aquilo que desrespeite seus princípios morais.

A escusa à qual os autores se referem é mais conhecida como objeção de consciência, que pode ser conceituada, de acordo com o filósofo político John Rawls (1997, p.408), como "a desobediência a uma injunção legal ou a uma ordem administrativa mais ou menos direta". Exemplos de objeção são dados pelo autor, como a de um pacifista que se recusa à prestação de serviço militar obrigatório, ou a de um soldado que se recusa à obediência de uma ordem contrária a uma força moral, ainda que em contexto de guerra, ou a de uma testemunha de Jeová em sua recusa na saudação à bandeira. Seja como for, é uma ação pública, não clandestina, da qual as autoridades estão cientes. Para Francione e Charlton (1992), a objeção de consciência ao uso de animais é uma questão de direitos civis, e não de direitos dos animais. Nas palavras de Laerte Fernando Levai (jun. 2007), promotor de Justiça de São José dos Campos (SP), a objeção de consciência é "um legítimo direito do estudante, que, de modo pacífico, o invoca não apenas para resguardar as suas convicções íntimas garantidas pela Carta Política, mas sobretudo para salvar a vida e poupar os animais de sofrimentos".

Afirmação 5: "Eu apoiaria e participaria de atividades que promovessem a substituição do uso de animais no ensino" 
Tabela 10: Porcentagem de Concordo (C), Discordo (D) e Nem Concordo Nem Discordo (NCND) entre estudantes de graduação em relação à afirmação 5

\begin{tabular}{|l|r|r|r|}
\hline Curso & \multicolumn{1}{|c|}{ C } & \multicolumn{1}{c|}{ D } & \multicolumn{1}{c|}{ NCND } \\
\hline BiSC & $90 \% *$ & $0 \%$ & $10 \%$ \\
\hline BiRS & $\mathbf{6 0 , 9 \% *}$ & $17,2 \%$ & $21,9 \%$ \\
\hline MeSC & $\mathbf{4 1 , 6 \% *}$ & $27 \%$ & $31,4 \%$ \\
\hline MeRS & $\mathbf{4 2 , 7 \% * *}$ & $20,9 \%$ & $36,4 \%$ \\
\hline FaSC & $39,7 \%$ & $20,6 \%$ & $39,7 \%$ \\
\hline FaRS & $\mathbf{4 3 , 1 \% * *}$ & $19,6 \%$ & $37,3 \%$ \\
\hline
\end{tabular}

*Ênfase forte; ** Ênfase moderada.

Fonte: Tabela elaborada pelo autor.

Novamente, todos os grupos sinalizaram concordância com a afirmação. Ênfases fortes foram observadas em três grupos (Biologias e MeSC), e moderada em MeRS e FaRS. O índice de sinalizações NCND (Nem Concordo Nem Discordo) nessa questão foi significativo nos três últimos cursos, como demonstrado na Tabela 10.

Esses dados sugerem que uma porção majoritária dos estudantes tem interesse em apoiar ou intervir favoravelmente na substituição de animais no âmbito do ensino. Por último, e a fim de determinar o nível de comprometimento dos estudantes que sinalizaram concordância, questionou-se com que tipo de atividade estariam dispostos a se envolver (Questão 6.1). Foram oferecidas as seguintes opções, com a possibilidade de escolher mais de uma: (A) Assinar um abaixo-assinado; (B) Doar dinheiro; (C) Participar de uma passeata; (D) Questionar o professor; (E) Promover debates em sala de aula; (F) Resgatar animais em laboratórios; (G) Apresentar oficialmente sua objeção ao uso de animais para sua faculdade. Níveis de envolvimento foram atribuídos para cada uma dessas opções, ficando assim categorizados: opções A e B - baixo nível de envolvimento; opções C, D e E - médio nível de envolvimento; opções F e G - alto nível de envolvimento. A opção G, em particular, foi considerada nesse nível, uma vez que há na literatura acadêmica registros de casos em que pedidos de objeção de consciência foram encaminhados à Justiça (Tréz, 2008) ou geraram situações de hostilidade e abandono de curso (Mirault-Pinto, 2008). A distribuição das opções entre os cursos pode ser verificada na Tabela 11.

Tabela 11: Distribuição, em percentual, das opções da questão 6.1

\begin{tabular}{|c|c|c|c|c|c|c|c|}
\hline & A & B & $C$ & D & $E$ & $F$ & G \\
\hline BiSC & $22,2 \%$ & $5 \%$ & $11,1 \%$ & $21,1 \%$ & $20 \%$ & $5 \%$ & $15,6 \%$ \\
\hline BiRS & $25 \%$ & $2,5 \%$ & $10,8 \%$ & $23,3 \%$ & $23,3 \%$ & $8,3 \%$ & $6,7 \%$ \\
\hline MeSC & $26 \%$ & $5,5 \%$ & $9,4 \%$ & $23,6 \%$ & $23,6 \%$ & $1,6 \%$ & $10,2 \%$ \\
\hline MeRS & $27,3 \%$ & $4,7 \%$ & $8,6 \%$ & $21,1 \%$ & $25 \%$ & $6,3 \%$ & $7 \%$ \\
\hline $\mathrm{FaSC}$ & $20 \%$ & $0 \%$ & $5,7 \%$ & $28,6 \%$ & $34,3 \%$ & $2,9 \%$ & $8,6 \%$ \\
\hline FaRS & $25,6 \%$ & $5,1 \%$ & $2,6 \%$ & $23,1 \%$ & $35,9 \%$ & $2,6 \%$ & $5,1 \%$ \\
\hline
\end{tabular}

Fonte: Tabela elaborada pelo autor. 
O comportamento foi similar nos diversos cursos no que diz respeito às três opções mais sinalizadas, indicando níveis baixo e médio de envolvimento. É importante destacar que a considerável frequência de sinalização da opção D é coerente com o apresentado na Tabela 4, na qual a intervenção junto ao professor foi a mais indicada pelos estudantes. Considerando todos os estudantes que concordaram com a afirmação ( $\mathrm{n}=217)$, o quadro se mostra mais claro: E (74,7\%), A (74,2\%), D (70\%), G (30,4\%), C $(28,1 \%), \mathrm{F}(14,7 \%)$ e B (12\%). Considerando todos os respondentes desta pesquisa, teríamos cerca de $40 \%$ deles potencialmente promovendo debates em sala de aula ou questionando seus professores, e cerca de $15 \%$ dispostos a resgatar animais de laboratório. Os dados reforçam a ideia de que tais práticas possuem alto poder gerador de conflito.

Quanto às opções de alto nível de envolvimento (F e G), podemos observar leve aumento da média na opção F para os cursos de biologia e medicina da UFRGS, tendo ocorrido o mesmo com a opção G na UFSC. Assim como casos de objeção de consciência encontram-se relatados tanto na literatura acadêmica (Mirault-Pinto, 2008) quanto na mídia (Vicária, 30 maio 2008; Mendonça, 8 maio 2009) - o resgate de um cão minutos antes de uma aula prática de fisiologia é relatado por Tréz (2003). Os riscos evidenciados (ou sugeridos) em ambos os casos e o relato denotam o alto nível de envolvimento de ações dessa natureza, o que pode explicar a baixa frequência pelas opções F e G.

\section{Três tipos de uso de animais no ensino: uma proposta}

Diante da questão de o sofrimento animal estar identificado em associação ao incômodo sentido, conforme os dados da pesquisa indicam, podemos definir três tipos de uso de animais no âmbito do ensino: prejudicial, neutro e benéfico.

No "uso prejudicial", provoca-se no animal algum tipo de dano (físico ou emocional), ou mesmo a sua morte, sem que isso seja feito em benefício dele, e sem que haja qualquer necessidade para o animal. Nesse tipo de uso, o animal é obrigatoriamente empregado como um instrumento didático descartável.

O "uso neutro" é aquele que não prejudica nem beneficia o animal que está sendo utilizado. Um exemplo de uso neutro são os estudos de observação de comportamento em que o animal em questão não é privado de nenhum tipo de necessidade básica nem submetido a uma situação intensa e prolongada de estresse. Nesse tipo de "uso", há a possibilidade de observar animais que já se encontram privados de sua liberdade, como os que vivem em zoológicos. Outro exemplo de estudo neutro é o uso post mortem de animais obtidos eticamente, como aqueles mortos naturalmente, em acidentes ou eutanasiados em clínicas ou hospitais veterinários em função de um quadro clínico irreversível.

O "uso benéfico" de animais é aquele no qual a prática da vivissecção, inclusive em situação de períodos idealmente mínimos de dor ou estresse para o animal, é realizado tendo em vista o benefício do animal utilizado. Pode parecer estranho empregar o termo "vivissecção" nesse caso, mas pensando que um animal tenha que passar por uma intervenção cirúrgica por motivos clínicos, ou mesmo para fins de castração, o termo é válido: o animal está sendo cortado vivo, porém com fins terapêuticos ou preventivos que visam à sua recuperação. O uso benéfico também pode abrir mão do procedimento da vivissecção, mas, ainda assim, justificar 
algum estresse em tratamentos não invasivos que visem, novamente, ao restabelecimento de um animal adoecido ou acidentado. Em todas as situações, o estresse (pré e pós-operatório, por exemplo) causado por procedimentos invasivos ou manipulativos com o animal deve ser o mínimo possível. No uso benéfico, o animal é tratado como um paciente de fato.

\section{Considerações finais}

Esta investigação pode levantar uma série de dados que reforçam a ideia de que o uso prejudicial de animais para fins didáticos tem um alto poder gerador de conflitos especialmente quando a percepção (ou o contexto) do sofrimento animal é identificada pelos estudantes. Assim, segundo os dados desta pesquisa, o conflito pode ser intensificado: (1) pela sensação de incômodo que o uso provoca em grande parte dos que participam desses procedimentos; (2) pelo significativo reconhecimento de que outras técnicas podem substituir animais em aulas práticas; (3) pelo indicativo significativamente majoritário de apoio ou participação em atividades que visem à substituição de animais; e (4) pelo também majoritário reconhecimento de que o uso não deve ser obrigatório. Quanto ao primeiro aspecto, vale ressaltar que tal sensação se mostrou tanto frequente entre os estudantes investigados como também predominantemente relevante. E para além de uma análise quantitativa, os motivos dessa sensação puderam ser associados a uma posição possivelmente fundamentada na preocupação com o animal experimentado, em que houve forte sugestão de sofrimento animal. Por outro lado, parece haver, ao mesmo tempo, posicionamento bastante conservador quanto à legitimidade moral e legal dos procedimentos didáticos com animais. Outra abordagem de pesquisa poderia lançar mais luz sobre essa importante questão, a fim de melhor compreender as justificações.

Seja como for, tal potencial de conflito traz importantes implicações para o campo da didática no ensino superior. Nessa perspectiva, a inovação das práticas educativas parece ser inevitável. Apesar de ser observada na academia uma força que procura preservar a "ordem, a rotina e as relações lineares de poder entre professores e alunos, parece haver energias externas, envolvendo exigências socioculturais que impulsionam os sujeitos docentes e discentes à mudança" (Cunha, 2007, p.20-21). Trata-se, assim, de uma questão com forte apelo social. Daí concluirmos que a migração do uso prejudicial de animais para novas abordagens e métodos de ensino, mais humanitários e modernos, deva ser implementada de forma ampla e justificada, a fim de suprir a abrangência da demanda e sua legitimidade enquanto processo de humanização do ensino, respectivamente.

\section{NOTAS}

\footnotetext{
${ }^{1}$ A sequência das questões é determinada de acordo com as respostas fornecidas pelo respondente.

${ }^{2}$ Um cabeçalho explicava que o termo "animal" dizia respeito apenas aos vertebrados (protegidos pela lei n.11.794/2008) e que a expressão "uso de animais" deveria ser compreendida como qualquer prática educacional envolvendo animais, que provoque morte intencional antes, durante ou após o experimento.

${ }^{3}$ Estendido pela exigência de aprovação do projeto no CEP/UFRGS e pelos calendários acadêmicos diferenciados (no caso do curso de medicina da UFRGS).
} 
${ }^{4}$ Programa de tratamento de dados qualitativos, versão 9.0.

${ }^{5} \mathrm{O}$ antropocentrismo é a situação do humano no centro de determinado universo, "em cuja órbita gravitam os demais seres, condicionando-os hierarquicamente de forma inferiorizada" (Almeida, 2010).

${ }^{6}$ Para saber mais sobre essa discussão, ver o livro $O$ direito e os animais (Rodrigues, 2003).

${ }^{7}$ Ver Jukes e Chiuia (2003) quanto aos aspectos humanitários dos métodos substitutivos.

\section{REFERÊNCIAS}

ALMEIDA, Paulo Santos.

Os direitos dos animais: antropocentrismo, tolerância e reflexão jurídico-ambiental. In: Magalhães, Valéria B.; Rall, Vânia (Org.). Reflexões sobre a intolerância: direito dos animais. São Paulo: Humanitas. p.71-91. 2010.

BALCOMBE, Jonathan.

The use of animals in higher education: problems, alternatives and recommendations. Washington, DC: HSUS. 2000.

BARBUDO, Carolina R.

O uso prejudicial de animais como recurso didático. Monografia (Graduação) - Universidade Federal de Alfenas, Alfenas. 2006.

CUNHA, Maria Isabel.

O lugar da formação do professor universitário: a condição profissional em questão. In: Cunha, Maria Isabel (Org.). Reflexões e práticas em pedagogia universitária. Campinas: Papirus. p.11-26. 2007.

DIAS, Thiago L.

Da vivissecção na educação: aspectos éticos e metodológicos do uso de animais vivos como recurso didático no ensino superior. Monografia (Graduação) - Universidade Estadual de Feira de Santana, Feira de Santana. 2011.

DINIZ, Renata et al.

Animais em aulas práticas: podemos substituí-los com a mesma qualidade de ensino? Revista Brasileira de Educação Médica, v.30, n.2, p.31-41. 2006.

FELIPE, Sônia T.

Ética e experimentação animal: fundamentos abolicionistas. Florianópolis: EDUFSC. 2007.

FRANCIONE, Gary; CHARLTON, Anna.

Vivissection and dissection in the classroom: a guide to consicentious objection. Jenkintown: The American Anti-Vivisection Society. 1992.

FREITAS, Henrique et al.

O método de pesquisa survey. Revista de Administração, v.35, n.3, p.105-112. 2000.

FRENCH, Roger.

Dissection and vivisection in the European

Renaissance. Aldershot: Ashgate. 1999.

GOMES, Gustavo M.

A percepção de estudantes de ciências biológicas e da saúde sobre o uso de animais vivos em aulas práticas na Universidade do Vale do Itajaí (Univali-SC).

Monografia (Graduação) - Universidade do Vale do Itajaí, Itajaí. 2009.

HEGEL, Georg W.F.

Princípios da filosofia do direito. São Paulo: Martins Fontes. 1997.

JUKES, Nick; CHIUIA, Mihnea.

From guinea pig to computer mouse: alternative methods for a progressive, humane education. Leicester: InterNICHE. 2003.

LEVAI, Laerte F.

$\mathrm{O}$ direito à escusa de consciência na experimentação animal. Pensata Animal, n.2. Disponível em: http://www. pensataanimal.net/index.php?option $=\mathrm{Com}_{-}$ content\&view=article\&id=105:o-direito-a-escusa $\&$ catid=46:laertelevai\&Itemid=1. Acesso em: 25 nov. 2013. jun. 2007.

LEVAI, Laerte F.; RALL, Vânia R. Experimentação animal: histórico, implicações éticas e caracterização como crime ambiental. In: Tréz, Thales de A. (Org.). Instrumento animal: o uso prejudicial de animais no ensino superior. Bauru: Canal 6. p.43-63. 2008.

LIMA, Wothan T.

Entendimento humano da experimentação animal. Ciência \& Cultura, v.60, n.2, p.26-27. 2008.

MARKUS, Regina P.

Legal, legítimo e ético: avanços da ciência busca do conhecimento. Ciência e Cultura, v.60, n.2, p.24-25. 2008.

MARQUES, Ruy G. et al. Rumo à regulamentação da utilização de animais no ensino e na pesquisa científica no Brasil. Ata Cirúrgica Brasileira, v.20, n.3, p.262-267. 2005.

MENDONÇA, Alba V.

Justiça autoriza aluna da UFRJ a não assistir aula com dissecação de animais. G1.

Disponível em: http://g1.globo.com/Noticias/ Rio/0,„MUL1112934-5606,00-JUSTICA+AUTORI $\mathrm{ZA}+\mathrm{ALUNA}+\mathrm{DA}+\mathrm{UFRJ}+\mathrm{A}+\mathrm{NAO}+\mathrm{ASSISTIR}+\mathrm{AULA}$ $+\mathrm{COM}+\mathrm{DISSECACAO+DE+ANIMAI.html}$. Acesso em: 25 nov. 2013. 8 maio 2009. 
MIRAULT-PINTO, Mariana C.

Objeção consciente ao uso de animais: o conflito na sala de aula. In: Tréz, Thales de A. (Org.).

Instrumento animal: o uso prejudicial de animais no ensino superior. Bauru: Canal 6. p.183-198. 2008.

MIRAULT-PINTO, Mariana Coelho; RÍMOLI, Adriana O.

Vivência dos estudantes das áreas biológicas, agrárias e da saúde da Universidade Católica Dom Bosco quanto ao uso de animais em aulas práticas. Biotemas, v.18, n.1, p.193-215. 2005.

NENÊ, Ulisses A.

Medicina da UFRGS ensina sem usar animais.

EcoAgência. Disponível em: http://www.

ecoagencia.com.br/?open=noticias\&id===AUUF0 dW1GdhJIRaVXTWJVU. Acesso em:

25 nov. 2013. 13 jul. 2009.

PAIXÃO, Rita L.; SCHRAMM, Fermin R.

Experimentação animal: razões e emoções para uma ética. Niterói: EdUFF. 2008.

PEREIRA, Júlio C.R.

Análise de dados qualitativos: estratégias metodológicas para as ciência da saúde. São Paulo: Edusp. 2004.

RAWLS, John.

Uma teoria da justiça. São Paulo: Martins Fontes. 1997.

REA, Louis M.; PARKER, Richard A.

Metodologia de pesquisa: do planejamento à execução. São Paulo: Pioneira. 2000.

REY, Fernando Luis G.

A pesquisa e o tema da subjetividade em educação. In: Reunião Anual da Anped, 24. , Caxambu. Anais... Caxambu: Anped. p.1-6. Disponível em: http://24reuniao.anped.org.br/ te7.doc. Acesso em: 25 nov. 2013. 2001.

RODRIGUES, Danielle T.

O direito e os animais. Curitiba: Juruá. 2003.

ROLLIN, Bernard E.

The moral status of animals and their use as experimental subjects. In: Kuhse, Helga; Singer, Peter (Ed.). A companion to bioethics. Oxford: Blackwell Publishers. p.495-510. 2009.

SHANKS, Niall; GREEK, Ray.

Animal models in light of evolution. Florida: Brown Walker Press. 2009.

SHOTWELL, Allen.

The revival of vivisection in the sixteenth century. Journal of the History of Biology, v.46, n.2, p.171197. 2013.

SMITH, Jane.

Dissecting values in the classroom. New Scientist, v.134, n.1820, p.31-35. 1992.
SOUSA, Analu.

Uso de animais para fins didáticos: percepção dos estudantes e professores dos cursos da área de saúde da FTC - Salvador. Monografia (Graduação) Faculdade de Tecnologia e Ciências, Salvador. 2007.

TAYLOR, Katy et al.

Estimates for worldwide laboratory animal use in 2005. Alternatives to Laboratory Animals, v.36, n.3, p.327-342. jul. 2008.

TRÉZ, Thales de A.

Métodos substitutivos. In: Feijó, Anamaria G.; Braga, Luisa Maria G.M.; Pitrez, Paulo Márcio C. (Org.). Animais na pesquisa e ensino: aspectos éticos e técnicos. Porto Alegre: EDIPUCRS. p.124-134. 2010a.

TRÉZ, Thales de A.

A produção sobre o uso de animais para fins didáticos: percepções em foco. In: Magalhães, Valéria B.; Rall, Vânia (Org.). Reflexões sobre a tolerância. São Paulo: Humanitas. p.147-174. 2010b.

TRÉZ, Thales de A.

"Não matarei": considerações e implicações da objeção de consciência e da desobediência civil na educação científica superior. In: Tréz, Thales de A. (Org.). Instrumento animal: o uso prejudicial de animais no ensino superior. Bauru: Canal 6. p.155-181. 2008.

TRÉZ, Thales de A.

O ensino anti-sensorial: os valores da vivissecção na educação científica. In: Guimarães, Leandro Belinaso et al. (Org.). Tecendo subjetividades em educação e meio ambiente. Florianópolis: NUP/ CED/UFSC. p.49-64. 2003.

TRÉZ, Thales de A.

$O$ uso de animais vertebrados como recurso didático na Universidade Federal de Santa Catarina: panoramas, alternativas e a educação ética. Monografia (Graduação) - Universidade Federal de Santa Catarina, Florianópolis. 2000.

TRÉZ, Thales de A.; NAKADA, Juliana.

Percepções acerca da experimentação animal como um indicador do paradigma antropocêntrico-especista entre professores e estudantes de Ciências Biológicas da Unifal-MG. Revista Alexandria, v.1, n.3, p.3-28. 2008.

VICÁRIA, Luciana.

A revolução dos bichos: a luta de um estudante de biologia para abolir as experiências com animais nas universidades. Época. Disponível em: http://revistaepoca.globo.com/Revista/Epoca/0," ERT4938-15224-4938-3934,00.html. Acesso em: 25 nov. 2013. 30 maio 2008.

YARRI, Donna.

The ethics of animal experimentation: a critical analysis and constructive christian proposal. New York: Oxford University Press. 2005. 